\title{
A LA MEMORIA DE LUIS ECHEGARAY QUIRÓS
} 1946-2009

\author{
Ved de cuán poco valor \\ son las cosas tras que andamos \\ y corremos, \\ que, en este mundo traidor, \\ aun primero que muramos, \\ las perdemos: \\ dellas deshaze la edad, \\ dellas casos desastrados \\ que acaescen, \\ dellas, por su calidad, \\ en los más altos estados \\ desfallescen.
}

(Jorge Manrique)

En noviembre de 2009 nos dejaba el Prof. Luis Echegaray Quirós. El conocimiento de la triste noticia nos produjo a todos un desgarrón interior que tan sólo el tiempo suturará. Pero en aquella mañana a muchos de los docentes e investigadores de la Facultad de Económicas de León nos pasó por la mente una rápida, exacta y fija pelicula de los años en los que vivimos y convivimos con Luis. Esos recuerdos, que boy guardamos como joya entre algodones, tenian sus origenes en la Escuela de Empresariales del Jardin de San Francisco. En nuestras conversaciones con un hombre sencillo, entrañable, sin dobleces, lleno de sabiduría popular -la sabiduría del oro viejo del vivir honesto de la que habla Dominguez. Berrueta al referirse a los hombres de esta tierra leonesa-, tuvimos el privilegio de percibir que Luis, ante todo, fue un hombre de bien.

No le corresponde al director de Pecvnia hablar de la trayectoria académica del Profesor Echegaray Quirós. Esa es una tarea que, por mutuo acuerdo, quedó encomendada a mi buen amigo y colega, el Profesor Placer Galán, Coordinador de este Monográfico que, en Memoria de Luis hemos titulado Studia Mercatoria Legionensia: Miscelánea de Marketing. Me toca, más bien, señalar su bonhomía.

Luis Echegaray fue un maestro de la palabra; casi siempre palabra escasa, precisa, pero eternamente profunda. El hombre deja a la tierra unos huesos y al aire un nom- 
bre, un nombre en la memoria de la palabra creadora que es la Historia, tejido de nombres. Para los que lo conocimos, el nombre de Luis es un nombre más duradero que los huesos, más que el bronce. Luis estaba impregnado del saber del pueblo, de la cultura que rezuman el café y la plaza pública. Su discreción, su apego a la tierra han sido fuente de enseñanzas para muchos de nosotros; enseñanzas que apreciamos más desde que se nos ha ido.

Luis nos ha dejado a destiempo, a descontrol de cuantos lo quisimos que fuimos muchos. En su haber están las amistades provenientes de las profesiones más diversas y de las cunas más sorprendentes. En su característico bumor de retranca, tan docto como socarrón, encontramos el justo retrato de su ser; de su ser esencial. Quizá baya que ignorar la realidad implacable de la muerte y decir muy alto que hay que vivir, porque lo que es morir, morir se acaba. Quizá.

Desde los recuerdos desordenados, desde la memoria todavia maltrecha, desde las frases descontroladas dominadas más por el corazón que por la razón, podríamos dedicar a Luis las palabras salidas a caudal de nuestro interior y canonizadas en su dia por el poeta Miguel Hernández, precisamente ante la desaparición de un amigo:

Yo quiero ser llorando el hortelano
de la tierra que ocupas y estercolas,
compañero del alma, tan temprano.

A las aladas almas de las rosas... del almendro de nata te requiero, que tenemos que hablar de muchas cosas, compañero del alma, compañero.

En efecto. Luis se nos ha ido tan temprano, tan callando, con sigilo, como si quisiera ahorrarse el trámite de pedirnos excusas por haberlo hecho. Su vida continúa y prosigue en sus hijos. Y habitará siempre en nuestros recuerdos. Abi, rodeado de afecto, con su sarcasmo y con su humor, vivirá para siempre.

En la Universidad de León, Facultad de Económicas, 24 de junio de 2010. 
El anuncio del fallecimiento de Luis Echegaray Quirós, el pasado mes de noviembre de 2009, fue un auténtico mazazo en la Facultad de Ciencias Económicas y Empresariales de León, y especialmente en el Área de Comercialización e Investigación de Mercados. Si desde finales del verano se había producido su baja por enfermedad, en ningún momento pensamos que se produciría el fatal desenlace.

En mi condición de primer Profesor del Área de Comercialización e Investigación de Mercados en la Universidad de León, tuve el honor de acompañar a Luis durante toda su carrera académica y compartir con él algunos proyectos de investigación y no pocas tareas de gestión universitaria en la antigua Escuela Universitaria de Estudios Empresariales.

Luis se incorporó a la Universidad de León el 15 de noviembre de 1985 desempeñando sucesivamente los puestos de Profesor Titular interino de Escuela Universitaria (del 15-XI-1985 hasta el 30-IX-1987), Ayudante de Escuela Universitaria (del 30-IX-1987 al 22-X-1992), y finalmente Profesor Titular de Escuelas Universitarias (desde el 22-X-1992 hasta su fallecimiento). Durante estos años su actividad docente se centró básicamente en disciplinas correspondientes a tres áreas temáticas: la gestión del comercio exterior, la dirección de ventas y las técnicas de investigación social. Dado el elevado número de alumnos que siempre han tenido Escuela Universitaria de Estudios Empresariales y posteriormente la Facultad de Ciencias Económicas y Empresariales de León, varios cientos de alumnos fueron formados por Luis.

Pero sin duda no creo equivocarme si afirmo que el mayor interés de Luis estaba en el ámbito del comercio exterior. En primer lugar, porque fue la asignatura que impartió ininterrumpidamente desde el curso 1986-1987, pero también porque fue el tema que eligió para desarrollar en su oposición al Cuerpo de Profesores Titulares de Escuelas Universitarias, en donde me correspondió la función de Secretario de la Comisión evaluadora, así como la materia que impartió en diversos cursos organizados por el INEM y la Cámara de Comercio. Finalmente, este interés por los temas de comercio exterior le llevó a integrarse en el Equipo investigador que a finales de los años ochenta formamos con los Profesores González García, Marín Rivero y Díez Modino, del Área de Economía Aplicada, para estudiar el comercio internacional de Castilla y León. De esta colaboración surgieron varias Comunicaciones al Congreso de Economía de Castilla y León, dos proyectos de investigación sobre las empresas exportadoras de Castilla y León, y un libro, pionero en su momento, sobre el comercio internacional de la recién constituida Comunidad Autónoma de Castilla y León.

Dentro del Área de Comercialización colaboró con los Profesores Placer Galán, Muñiz Martínez y Vázquez Burguete en la redacción de varias Comunicaciones sobre estrategias de marketing internacional de las empresas exportadoras 
de Castilla y León presentadas en los Encuentros de Profesores Universitarios de Marketing y en la Reunión de Estudios Regionales de la Asociación Española de Ciencia Regional.

Formando equipo con los Profesores Bello Acebrón, primer Catedrático del Área de Comercialización e Investigación de Mercados en la Universidad de León, y Placer Galán, se implicó en otros proyectos de investigación, en la primera mitad de los noventa, tales sobre la actitud a la innovación de las pequeñas y medianas empresas industriales de Castilla y León, la elaboración de un modelo informático de Plan de Marketing para el CEI de Castilla y León, la evolución del sector de la pizarra en la provincia de León y la demanda de nuevas titulaciones en la Universidad de León. Por otra parte, con el Profesor Alba Alonso, de la Universidad de Oviedo, colaboró en el estudio socioeconómico de la comarca de los Picos de Europa.

Cuando fui nombrado Director de la Escuela Universitaria de Estudios Empresariales, en enero de 1987, mi primera decisión fue proponer a Luis para desempeñar el cargo de Secretario de la Escuela, obteniendo el respaldo unánime del Claustro de Profesores. Durante todo mi mandato, hasta el año 1995, Luis desempeñó el cargo con dedicación, lealtad y eficacia. Fue un colaborador siempre dispuesto a ayudar y su talante tranquilo resultó básico en los momentos difíciles, cuando no tensos, que a veces se producen en los cargos de gobierno.

Cuando estábamos comenzando a preparar este Monográfico se produjo el fallecimiento de Luis y por ello queremos dedicarlo a su memoria. Los artículos que en él se incluyen corresponden a distintos investigadores del Área de Comercialización e Investigación de Mercados y a una serie de Profesores de otras universidades, españolas y extranjeras, que mantienen una relación directa con nosotros. A todos ellos queremos agradecerles su respuesta afirmativa a nuestra demanda de colaboración en la elaboración del Monográfico y la amistad que nos profesan. La variedad de temas abordados y de Profesores participantes pretende reflejar las líneas de investigación que se desarrollan en el Área de Comercialización e Investigación de Mercados de la Universidad de León y confiamos resulten de interés para el lector. 